\title{
Research on modern agricultural investment cooperation between Yunnan province and GMS countries
}

\author{
Zidong Zhu \\ Foreign Economic Cooperation Center \\ Ministry of Agriculture \\ Beijing, China \\ zhuzidong@agri.gov.cn \\ Zhaojing An* \\ International Business School
}

\author{
Yunnan University of Finance and Economics \\ Kunming, China \\ anzhaojing@163.com \\ Xiaoli Zhu \\ College of Economics and Management \\ Yunnan Agricultural University \\ Kunming,China \\ lily7277@163.com
}

\begin{abstract}
As China's Regional Center of radiation for Southeast Asia and South Asia, and Yunnan Province has good economic strengths and locational advantages in modern agricultural investment cooperation between China and GMS countries, cooperation is of great significance. This article analyses on the current situation of agricultural development in GMS countries and the status of agricultural investment in Yunnan Province to GMS countries, so as to put forward feasible suggestions to promote modern agriculture investment cooperation between Yunnan Province and GMS countries better.
\end{abstract}

Keywords-GMS countries; modern agricultural; investment cooperation

\section{BACKGROUND}

Although GMS countries have good natural resources in agriculture development, while they are limited by backward factors such as technology, economy, and agricultural development are in traditional agriculture stage. However, China's modern agricultural development level is more and more higher, the supply is insufficient, therefore, both sides of the modern agricultural investment cooperation are of great significance. Yunnan, an important province in China adjacent to GMS countries, who has a unique regional advantage in investment cooperation and industrial foundation in the GMS countries Modern Agricultural Cooperation.

Modern agriculture refers to Socialized Agriculture by applying modern scientific technology and modern industry, provides means of production and scientific management methods. With the development of economy, traditional agriculture converting to modern agriculture is an inevitable trend. Huiqiong Jiang (2012) pointed out that the current status of agricultural cooperation development between Yunnan province and Southeast Asia countries, who proposed a series of development strategies that Yunnan province should increase capital and technology, and enhance the

\footnotetext{
* Corresponding author
}

competitiveness of enterprises [1]. Shuang Li (2013) who analyzed the current characteristics and trends of agricultural products in Yunnan's economic development, and put forward specific measures on the base of two different cooperation and development modes, from four aspects like constructing policy system, promoting industrial development, establishing support platform and enhancing the strength of enterprises [2]. Yue Han(2014) pointed out that Burma agricultural development is highly complementary, the establishment of modern agricultural cooperation and exchange area is conducive to bilateral upgrade of industrial structure, increasing trade and investment between China and Myanmar [3]. Yaqiang $\mathrm{He}(2016)$, who studied situation of modern agricultural cooperation and exchanges between China and Laos, provided a realistic basis for subsequent research between this two countries. In addiction, he presented specific development condition within two countries on trade products, research and personnel exchanges, technology transfer etc [4].

Current research achievement mainly related to agricultural economic development, present situation and existing problems of communication and cooperation between China and Developed Countries. The perspective of this paper is based on the agricultural status of GMS countries, analyzes internal and external environment of modern agriculture development in Yunnan Province, in terms of investment and cooperation, put forward feasible countermeasures to facilitate cooperation in modern agriculture development between Yunnan and GMS countries.

\section{ANALYSIS ON THE OPPORTUNITY OF MOFERN AGRICULTURAL COOPERATION BETWEEN YUNNAN PROVIENCE AND GMS}

\section{A. Geographical advantage}

GMS four countries are adjacent to the southwest of China, and in which the three countries bordering with China, north of Laos, northeast of Myanmar, north of Vietnam adjacent to 
Yunnan Province. And Vietnam and Laos are the main channels from China to other ASEAN countries, Burma is an important bridge between South Asia and Southeast Asia. Myanmar is an important bridge of communication between GMS countries. Meanwhile, GMS national geographic location is similar, and most areas of the GMS countries belong to the tropical monsoon climate, so the main crop species, the level of industrial development and major industry conditions of the GMS countries have many similarities. In addition, the three countries of Vietnam, Laos, Myanmar also have a certain similarity in the domestic consumption levels, consumption preferences, and many other aspects [5].

\section{B. Agriculture is the main industry}

Although the level of industrial development in GMS countries gradually improve, but agriculture is still the main industry, and the proportion of agricultural population is relatively large. In addition to the industrial development of Vietnam and Thailand is in relatively high level, the proportion of agriculture in the national economy of Laos and Myanmar are above $30 \%$. Table 1 shows that the higher level of industrial and service sector development in Vietnam and Thailand, which is due to the higher national economic reform policies; The three largest industrial sector of Laos accounts for the relative average, agriculture accounts for more than $30 \%$, industrial development level is low, but the proportion of service industry is higher than agriculture, the reason lies in the positive development of the Laos tourism industry; Myanmar's agriculture accounts for more than $40 \%$, the remaining two industries are relatively low, because of domestic political instability, leading to inefficient use of natural resources and tourism resources in Myanmar.

TABLE I. 2012 The OUtPut VAlue of THE THREE MaJor SEctors OF THE GMS COUNTRIES PROPORTION OF GDP (UNIT:\%)

\begin{tabular}{|c|c|c|c|}
\hline National & Agricultural & Industry & Service \\
\hline Vietnam & 20.9 & 41.1 & 38.1 \\
\hline Laos & 31.3 & 33.6 & 35.1 \\
\hline Myanmar & 40.0 & 26.0 & 34.0 \\
\hline Thailand & 8.4 & 47.1 & 44.4 \\
\hline
\end{tabular}

Industrial development of GMS countries is basically dominated by agriculture, the low level of national infrastructure and economic development makes domestic natural resources cannot be fully realized. GMS countries actively carry out economic reform, improve the domestic investment environment, develop foreign trade, and gradually open up the domestic market.

\section{Improve the degree of opening up}

GMS countries carry out economic reform vigorously, improve the degree of openness, and participate in international and regional economic cooperation. In order to attract more foreign investment, the four countries adopt policies to encourage foreign investment and export, revise and improve laws and regulations and other ways to improve the domestic investment environment. For example, Myanmar enacted the new law of "Investment Law", which points liberalize owned corporate equity, land usage term and other aspects for foreign investor in Myanmar.

TABLE II. 2000-2014 TOTAL VOLUME OF IMPORTS AND EXPORTS OF GOODS IN GMS COUNTRIES (UNIT: USD BILLION)

\begin{tabular}{|c|c|c|c|c|}
\hline Year & $\mathbf{2 0 0 0}$ & $\mathbf{2 0 0 5}$ & $\mathbf{2 0 1 0}$ & $\mathbf{2 0 1 4}$ \\
\hline Vietnam & 300.87 & 692.03 & 1570.76 & 2997.36 \\
\hline Laos & 8.65 & 14.35 & 38.06 & 59.50 \\
\hline Myanmar & 40.47 & 57.40 & 135.56 & 272.57 \\
\hline Thailand & 1309.81 & 2291.14 & 3782.35 & 4555.26 \\
\hline
\end{tabular}

Table 2 shows that the total amount of imports and exports of goods in the four countries gradually increased from 2000 to 2014, reflecting the openness of the four countries is improving. Since 2010, China has become the second largest economy in the world. And in 2014, China was the largest trading partner of the ASEAN, the amount of exports and imports were $\$ 150.4$ billion, \$ 216.1 billion, therefore it must be critical choices that actively promote border trade and economic exchanges with China, and attract Chinese enterprises to invest in the country for the GMS countries in promoting national economic development, reform and openness.

\section{OPPPRTUNITIES AND CHALLENGES OF YUNNAN'S AGRICULTURAL INVESTMENT IN GMS COUNTRIES}

\section{A. Opportunities of foreign investment in agriculture in Yunnan province}

\section{1) Status of Agricultural Foreign Investment}

From 2005 to December 2013, Yunnan Province has set up 118 overseas agricultural investment enterprises, accounted for $26.82 \%$ of the total number of foreign investment enterprises in Yunnan Province, and investment companies are mainly concentrated in GMS countries, the largest number of investment enterprises in Laos, reaching 79, accounting for $66.95 \%$ of the total number of foreign agricultural investment.

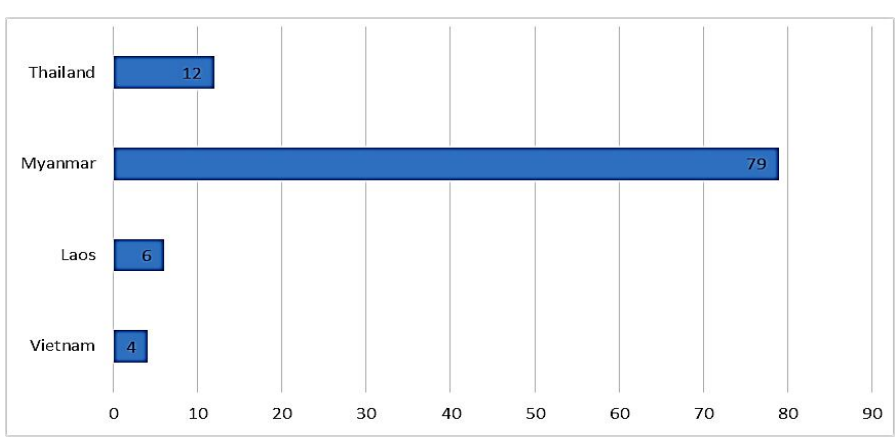

Figure. 1. 2005 to December 2013 Yunnan Province agricultural enterprises overseas investment country distribution

From 2005 to December 2013, there are 118 overseas agricultural investment enterprises in Yunnan Province, and 88 owned enterprises, accounting for $81 \%$ of the total investment 
companies; 20 joint ventures, accounting for $19 \%$ of the total investment enterprises.

Agricultural foreign investment of Yunnan Province started earlier, it is the peak period of agricultural "going out" investment development from 2005 to 2010, it has set up 96 Agricultural Foreign Investment Enterprises. From 2011 to 2013, there are 16 agricultural foreign investment enterprises have set up, the pace of new enterprises slowed down, and investment projects have increased.

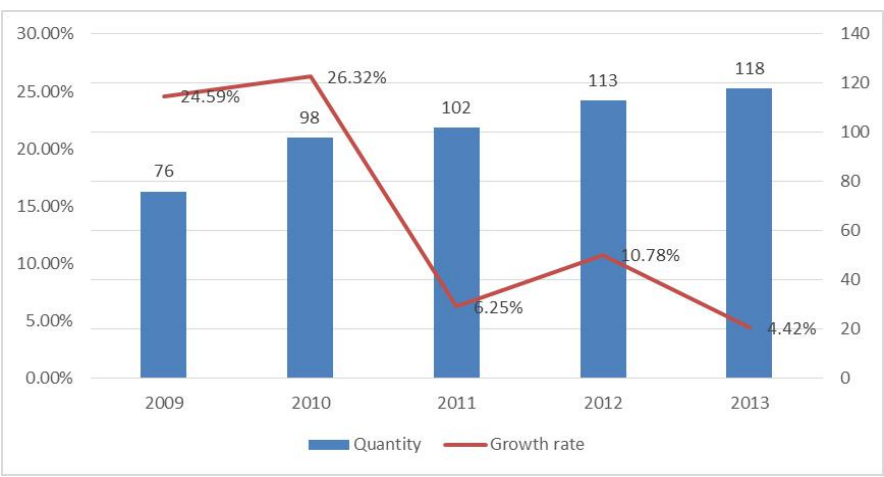

Figure. 2. 2009 to 2013 the number and growth rate of agricultural enterprises in Yunnan province

Based on the statistics of the overseas investment data of 57 representative overseas investment agricultural enterprises in the province, in the field of grain crops, the planting area of maize is the largest, followed by rice, and the food crops area is 41537.69 hectares and the production is 285263.50 tons; economic crops, the planting area, production and export volume of natural rubber are the largest, and Cash crop area is 101745.1 hectares, output is 76119.92 tons; production of animal products, animal products are mainly pork, pig farm area is 20 hectares, but the herds is unknown.

\section{2) External environment of foreign agricultural investment} in Yunnan Province

Yunnan is located in China's southwest border, and has the advantage of international trade and logistics center for our country connection GMS countries, and has obvious advantage in developing modern logistics. Meanwhile, the government has vigorously carried out the openness to the outside world, the foreign ports have been gradually increasing, and the import and export has greatly promoted the economic development. Relatively, Thailand pay more emphasis on the development of agricultural technology and seeds, and actively practice.

In addition, the arable land development level of GMS countries is relatively low, only $50 \%$ of the total area, and the national irrigation area is basically less than 50\%. GMS countries are agriculture-based economy in developing countries, small-scale agricultural development, low level of mechanization. Agricultural technology of other countries has just started, the level of development is still backward. Although the growth rate of country GDP is about $6 \%-7 \%$, the agricultural investment growth rate is less than 3\%, even less than $1 \%$. So, the modern agricultural investment cooperation between Yunnan province and GMS countries has great potentiality.

\section{B. Challenges of Modern Agricultural Cooperation between Yunnan Province and GMS countries}

1) Tight buy-back quota and issued timeliness is not strong

Yunnan province buy-back quota of overseas agricultural investment and development company products mainly through the alternative planting projects to complete. If companies do not have the quota index, which need to pay over $20 \%$ tariff $17 \%$ value-added tax for buy-back products. Although the quota is allocated two times a year, the timeliness is not strong, so the guidance for overseas agricultural production is not strong.

2) Financing difficulties, exchange rate risk and other financial problems

The Yunnan branch of the National Development Bank is the largest financial institution of foreign currency loans in Yunnan province. However, due to the long investment cycle of agriculture, and the repayment rate is not guaranteed, so the bank only give attention to the "going out" flower projects. While it implements strong foreign exchange control for other agricultural areas of investment enterprises in GMS countries, so that enterprises can only take cash out of the country or take other higher risk of investment approaches, affecting the development of the province's enterprises in the GMS national agricultural investment.

3) "Going out" agricultural enterprises mostly alone, and scale effect is low

Now although there are many agricultural investment enterprises of in GMS countries, but they are fighting with each other, win-win cooperation of enterprises are few. So most of the agricultural investment enterprises of Yunnan Province engaged in growing, processing, weaker, not formed a complete industrial chain in GMS countries.

\section{4) Lack of financial support}

Yunnan Provincial Department of commerce is responsible for the financial assistance to foreign investment enterprises, about 40 million yuan every year, and requires each enterprise to apply the amount cannot be more than 2 million yuan, it is unable to meet the requirements of long-term investment in agricultural investment completely. And government procedures involved in the immigration issues of people, products and other integrated services are very complicated, seriously restricting the development of foreign enterprises.

\section{THE Mode of MOdern Agricultiral COOPERRATION BETWEen YunNAN PROVIENCE AND GMS COUNTRIES}

\section{A. Yunnan province and GMS national modern agricultural investment and trade mode}

1) “Going out" investment model

The modern agricultural cooperation between Yunnan province and GMS national is still in its initial stage, although there are some similarities in the natural and social economic environment of GMS countries, the differences in the development of agriculture still exist in different countries. Its investment cooperation environment is complex, and the foreign investment in Yunnan province is mainly owned by the 
State-owned enterprises, though lack of participation of private small scale enterprises. Therefore, large, medium and small enterprises should be encouraged to participate in the foreign investments, so that promote the cooperative effect.

Meanwhile, we should implement different types of investment for different business needs. For example, the enterprises implement market oriented investment which need to expand the scale of product sales in the international market to carry out cross-border investment of enterprises; the enterprises implement resource oriented investment which need some kinds of resource from abroad; the foreign investment enterprise implements efficient investment which need to reduce the cost and increase the profits; and the enterprises implement strategic investment which are to promote the international competitiveness, etc.

\section{2) "Bring in" investment model}

The introduction of foreign capital can make up the shortage of agricultural investment in Yunnan province. The introduction of advanced management experience and technology can drive the development of agricultural exportoriented economy. But to do a good job in the introduction of foreign investment, we must proceed from two aspects: on the one hand, exploring the channels and ways of the introduction of foreign capital, such as Yunnan Province introduce foreign investment substantially, take financing cooperation for high technology content and high value-added projects, find new ways or host Expo to attract foreign investment, and set up foreign capital project database, such as CA-EXPO. On the other hand, improve agricultural investment environment, and enhance attractive force, we should develop and improve the use of foreign investment laws, regulations and preferential policies, strengthen the construction of infrastructure in the province, and create a better environment for agricultural investment according to local conditions [5].

\section{3) “Step by Step” investment model}

Modern agricultural cooperation is a long-term process, the focus of investment is not the same in different stages of development. So taking the "step by step" investment model is a good choice. Modern agricultural investment of Yunnan Province in GMS country's is divided into three stages: the first stage, the initial stage of agricultural raw material investment, investment amount is small; the second stage, take advantage of the local cheap labor as the main growth stage, export oriented small enterprises as the mainly; the third stage, high level of cooperation in the rapid growth phase, the stage is no longer limited to funds, technology, information, and other aspects of the investment were increased.

\section{4) Market oriented diversified trade cooperation mode}

Agricultural trade cooperation between Yunnan and GMS countries must be guided by the market. Market oriented trade cooperation can eliminate the subjectivity and blindness of product development, achieve the diversification of products and markets, and promote the diversification of trade structure. To a certain extent, the diversification of trading institutions can avoid the risk of trade caused by fluctuations in demand, and carry out different forms of agricultural trade cooperation learning multi advanced planting and R\&D technology, and in different countries, so that promote the development of the two sides.

5) "Take the enterprise as the leading, Government as a pillar" cooperation model

Enterprises have their own advantages in financing and management operation. The agricultural trade cooperation should take the enterprise as the leading, but the government's position in the trade cooperation cannot be ignored. And the Yunnan Provincial Department of agriculture did a survey about the representative of the agricultural enterprises, the results show that $76 \%$ of the enterprises cannot get sufficient information of the market or policy. Therefore, it is very important for enterprises to provide information consulting services that establish and perfect the government information collection and release system. So taking the enterprise as the leading and the government as the pillar of the trade cooperation mode can achieve the smooth progress of bilateral trade cooperation.

\section{B. Science and technology in agriculture cooperation mode of Yunnan Province and GMS countries}

1) Mode of agricultural science and technology experiment and demonstration

Compared with Vietnam, Laos, Myanmar and Thailand, Yunnan Province has a comparative advantage in agricultural farming and other technical aspects, and has more experience in the cultivation of improved varieties and integrated pest control, and at a leading level in the promotion of agricultural science and technology and training and biotechnology, etc. It can establish a Characteristic science and Technology Park of agricultural products at the junction of the region of Yunnan and GMS countries, formation region scale benefit. Using cross-border agricultural science and Technology Park can improve the level of multilateral modern agricultural cooperation and promote the development of the industry.

\section{2) Enterprise joint model}

Business-led development model, is bound to give full play to the advantages of inter-enterprise product and technical cooperation. Product combination is mainly through mergers foreign enterprises or joint the implementation of holding to integrate similar enterprises into a complete industrial chain, and using the advantages of each enterprise, improving product competitiveness and open up the market, and then achieve a "win-win" situation. Technology alliance is the cooperation between enterprises in the province and the enterprises in GMS countries mainly through technical output, cooperation in R \& D and other means, etc, thus changing their backward production technology, upgrade the level of agricultural enterprises, improve the level of modern agricultural development [6].

\section{3) Cooperation model of scientific research institutes}

The mode of cooperation in scientific research institutes is dominated by research institutes, including joint establishment of schools and the establishment of a national public cooperation platform. Joint establishment of the school is to jointly develop agricultural science and technology personnel, then understand the agricultural advantages of various 
countries and exploit and utilize resources. The national public cooperation platform of Yunnan and GMS is a special agricultural laboratory established jointly by universities and research institutes, and research results are shared by the partners [7].

\section{4) Technology intermediary mode}

Technology Agency is mainly aimed at private and small medium enterprises, providing laws and regulations, policies and corporate information, establishing communication and other services. The intermediary institutions with stronger strength can provide market research, technology verification, project evaluation and other deeper services. Through technical intermediary, enterprises can better understand information of the market, related enterprises, and cooperative project, etc. so that promote the development of the project. The government of Yunnan province has provided some relatively mature non-profit technology intermediary, such as Yunnan provincial science and technology exchange center, Yunnan province rural science and Technology Service Center, Southeast Asia and South Asia economic Trade Cooperation Development Association, etc.

\section{Struategies to Better Promote Modern AGRICULTURAL INVESTMENT COOPERATION BETWEEN YUNNAN PROVIENCE AND GMA COUNTRIES}

Based on the above analysis and research, Yunnan province has the advantage of developing plateau agriculture, and is fully capable of utilizing industrial advantages and regional advantages for the development of agricultural investment in GMS countries, to effectively integrate agricultural resources at home and abroad, and taking advantage of the comprehensive strengths both country and province, actively developing investment cooperation with GMS countries in agriculture, which can improve the formation of agricultural industry chain , and enhance its international competitiveness and become the regional leader in agricultural innovation and service providers. Specific measures are as follows:

Firstly, set up a special fund to give strong financial support. It recommends that Government sets up a special fund of agricultural cooperation, the implementation of government support through the fund platform, support by domestic and foreign agricultural policy convergence, and gives special loans to deep processing, logistics, warehousing and other key projects, export-oriented agricultural policy to give preferential loans, outside the United Nations development finance, and expands the scale of investment in agriculture and cooperation in GMS countries [8].
Secondly, create a "Big Project" platform, and fully exploiting all aspects policy potential in cooperation, test area, FTA. Using multilateral cooperation mechanisms to speed up the agricultural infrastructure facilities. Agricultural cooperation and agricultural infrastructure are included in the scope of multilateral cooperation, and ask for the investment policy from the host country.

Thirdly, improve the government services. It should constantly improve the mechanism of government investment and cooperation on export-oriented agriculture, and comply the trade facilitation of investment, the establishment of specialized economic platform for foreign investment in agriculture, providing the latest market and economic information and business information services for the company. At the same time, it needs to popularize of the laws and regulations of the country of cooperation, technical standards, and establishes a unified agricultural product quality standards.

Fourthly, fostering large-scale agriculture multinational group. It means to cultivate a number of internationally competitive Chinese characteristics and agricultural investment team, which can enhance the overall strength of agriculture, to achieve "powerful combination", "the strength of the joint", to enhance their position in the industrial chain, to obtain the right to speak.

\section{REFERENCES}

[1] H.Q. Jiang, "Under bridgehead strategy of opening up and cooperation of Yunnan Agricultural Research", Chinese Agricultural Science Bulletin, vol. 28, 2012, pp. 135-139.

[2] S. Li, "Yunnan - ASEAN agro-industry model of regional cooperation research," Wuhan: Wuhan University of Technology, 2013.

[3] Y. Han, "The conception of the construction of modern agricultural industrial park between Yunnan Province and Myanmar," Economies research of the Indian Ocean, 2014.

[4] Y.Q. He, "Recommends that China and Laos agriculture economic cooperation and exchanges," The financial economy, 2016.

[5] H.X. Zhao, "the study of the investment opportunities in Vietnam, Laos and Myanmar for China," Yunnan University, April 2015.

[6] C. Liao, T.F. Zhu, and Z.R. Huang, "Development trend of Agricultural products deep processing technologies and countermeasures in the $21 \mathrm{~s}$ century," Transactions of the Chinese Society of Agricultural Engineering, 2004

[7] K.O. Dimitrios, "Challenge of Technological Development for ASEANIntraregional and International Co-operation," Singapore Institute of Southeast Asian Studies: ASEAN Economic Bulltetin, vol. 19, pp. 106, April 2002.

[8] M. Shi, "Study on the strategy of agricultural development in Laos," Northwest A \& F University,2014. 